March 6, 1998

\title{
Empirical Puzzles of Chilean Stabilization Policy ${ }^{1}$
}

\author{
by
}

\author{
Guillermo A. Calvo \\ Center for International Economics \\ University of Maryland \\ College Park, MD 20742
}

\author{
Enrique G. Mendoza \\ Department of Economics \\ Duke University \\ Durham, NC 27708
}

This paper reviews Chilean stabilization policy during the 1990s and argues that, while the merits of Chilean policy should be praised, there are four puzzles in conventional interpretations of the Chilean experience worth studying. First, the policy of targeting indexed interest rates does not coincide with a policy of targeting real interest rates. Second, there is no systematic link between the decline in inflation and the upward adjustments in indexed interest rates. Third, changes in the exchange rate and in the performance of the external sector help explain the decline in inflation. Fourth, the strong cyclical growth of the real economy was influenced in part by the large and persistent increase in the world price of Copper. We provide statistical evidence favoring these arguments using recursively-identified vector-autoregression models, and sketch a model of staggered pricing under indexation that sheds some light on the Chilean case.

${ }^{1}$ This paper was prepared for the seminar on Chile Development Lessons and Challenges organized by the Economic Development Institute of the World Bank and held in Washington D.C., December 17-18, 1997. We thank Alejandro Izquierdo for valuable research assistance, and also thank comments by Sebastian Edwards, Jose De Gregorio, Saul Lizondo, Roberto Zahler, Andres Velasco and other seminar participants. 


\begin{abstract}
"Central bankers and even some monetary economists talk knowledgeably of using high interest rates to control inflation, but I know of no evidence from even one economy linking these variables in a useful way..."

(Robert E. Lucas, Jr.: Nobel Lecture: Monetary Neutrality, Journal of Political Economy, August 1996, p. 666)
\end{abstract}

\title{
1. Introduction
}

The performance of the Chilean economy during the 1990s has been impressive. After recovering from the severe recession that followed the financial crash of 1982 , Chile maintained a record of sustained high economic growth in an environment of controlled public and current account balances, tight fiscal and monetary policies, low and declining inflation, high saving rates, and low unemployment. During this period Chile also continued with its pioneering program of economic reform by building on the far-reaching reforms introduced in the previous two decades. ${ }^{2}$ Thus, in sharp contrast to the ongoing struggle of other Latin American nations to stabilize their economies and escape recession, Chile seems to have attained what has proved elusive for most countries in the region: sustainable high growth. The Chilean miracle continued despite the region-wide sudden outflow of capital triggered by the Mexican crash of December, 1994, and it is also expected to continue despite the turmoil of financial markets in East Asia.

In light of this impressive performance, there is growing interest in studying Chile's experience, with the aim of identifying the driving forces behind the strength of the Chilean economy and determining whether Chile's main accomplishments can be reproduced in other countries. There has been a natural tendency to attribute the Chilean success to the country's macroeconomic policies (see, for example, Dornbusch et al., 1995, and Williamson, 1997), but at

${ }^{2}$ Corbo et al. (1996) provide a detailed review of Chilean stabilization and structural reform policies since the 1970 s. 
the same time there has also been a tendency to oversimplify the issue and make the argument that the economic problems of other developing countries can be solved simply by adopting Chile's policies. In contrast, in this paper we argue that, while the merits of Chile's sound policies are not to be undervalued, the fact of the matter is that our understanding of Chile's experience is limited. There is little formal empirical evidence linking Chile's stabilization policy framework to the gradual deceleration of inflation, and little is also known about the extent to which the cyclical performance of the economy was influenced by important exogenous developments -- particularly the large and persistent increase in the world price of Copper and the surge in private international capital inflows. Without a clear understanding of the role of policy vis-a-vis exogenous factors in explaining Chile's economic performance, it is difficult to establish whether the dynamics exhibited by the Chilean economy were the outcome of a policy-led process of smooth convergence to sustainable growth or of the stages of an endogenous process triggered by exogenous shocks.

In this paper we make a case to argue that (a) there is an important flaw in the conventional wisdom that views the management of indexed interest rates by the Central Bank of Chile as means of conducting monetary policy by directly managing real interest rates, (b) factors other than stabilization policies have played an important role in Chilean economic performance, and (c) the dynamics exhibited by key macroeconomic aggregates can be interpreted in part as an endogenous process of adjustment triggered by exogenous shocks. In making this case, we document statistical analysis and explore briefly some complex analytical issues that may help broaden our understanding of the Chilean experience.

We conduct our analysis in the light of a statistical framework that aims to integrate key elements of policy management, the external environment, and the endogenous dynamics of 
macroeconomic variables. This framework is an application of the identified Vector Autoregression (VAR) econometric technique introduced for the analysis of U.S. monetary policy by Sims (1992). In particular, we adopt a variant of this technique recently developed by Christiano, Eichembaum, and Evans (1997): the recursive identification approach. This approach proposes a straightforward method to isolate the effects of exogenous policy shocks on macroeconomic dynamics from the endogenous response of policy instruments to systematic changes in the economic environment. We view the characterization of the observed dynamics of the Chilean economy produced by this analysis as the set of empirical regularities that a macroeconomic model should aim to explain, and we provide some rough guidelines discussing the minimal elements of such a model. In particular, we argue that some features of the Chilean experience could be consistent with a model of forward-looking, staggered-price setting under conditions of widespread (but imperfect) indexation, although the formal development and testing of this model is beyond the scope of this paper. ${ }^{3}$

The paper is organized as follows. The next section reviews the most salient features of Chilean stabilization policy in the 1990s. Section 3 discusses some basic flaws in the conventional interpretation of the Chilean policy framework, and develops the statistical model that helps us interpret the role of policy variables vis-a-vis exogenous factors in explaining Chile's macroeconomic performance. Section 4 concludes and draws some policy lessons.

\section{Chilean Stabilization Policy and External Factors in the 1990s}

The general strategy of stabilization policy implemented in Chile in recent years was

\footnotetext{
${ }^{3}$ Note also that the need to keep the study focused on stabilization policy in the $1990 \mathrm{~s}$ forced us to set aside several key aspects of the Chilean experience -- such as the strategy for resolution of the 1982-83 banking collapse and the privatization of the pension system.
} 
consistent with long-run objectives developed in the context of the package of policies implemented in the aftermath of the 1982 crash. In particular, the primary goals at the center of the Chilean strategy were: (a) to attain a high and sustainable GDP growth rate with a gradual decline in inflation, while ensuring that (b) the fiscal and current account deficits are kept under control, and (c) the international competitiveness of the economy is preserved. The actual policies implemented to achieve these goals, the priority assigned to each one, and the quantitative interpretation given to the adjectives in italics has varied over time, depending on the performance of the economy and changes in the world environment and in the views and preferences of policymakers. For example, between 1985 and 1989 inflation was contained but did not decline significantly (as it oscillated around 20 percent), and after that it declined gradually. The current account as a share of GDP averaged 4.5 percent in 1985-89, while in 1990-96 averaged 2 percent of GDP. The real exchange rate appreciated in $1985-89$ by about the same amount that it depreciated between 1990 and 1996 (about 4.7 percent).

A simplified representation of the policy mix of the 1990s is as follows:

(a) Monetary and Exchange-Rate Policies

Monetary and exchange-rate policies have been the key instruments used to make progress in the gradual deceleration of inflation, and in maintaining the real value of the Chilean peso within limits regarded as consistent with Chile's external competitiveness. The preferred instrument of monetary policy has been the management of short-term interest rates imperfectly indexed to the monthly change in the CPI through daily adjustments in an artificial unit of account known as the Unidad de Fomento (UF). The mechanism for managing interest rates has changed over the years. In the late 1980s the aim was to influence short-term interest rates so as to 
produce desired targets of monetary aggregates. In the early 1990s there was a switch to a system of direct sales of 90-day bills that constituted liabilities of the central bank (and hence should not be given the same interpretation of a conventional open market operation, in which liabilities from the central government are bought or sold by the central bank in a secondary market). In the last two years there was a switch to a regime of inflation targeting, in which the aim has been to manage monetary policy by influencing overnight interbank interest rates to conform with preannounced annual inflation targets.

The central bank built a strong reputation and gained credibility by pursuing active monetary tightening to fight inflationary pressures and cool down the economy when clear signs of overheating emerged. One episode of this tightening is particularly notable: the so-called Sobreajuste (over-adjustment) of 1990, in which indexed interest rates were increased by an unprecedented magnitude from about 8 to 16 percent. The real economy reacted to the change in policy, but inflation was very slow to respond and in fact for several months it increased instead of falling. This is particularly notorious because in Chile any small surge in inflation is rapidly magnified by the extremely high degree of indexation of the economy -- all prices of durables are regularly quoted in UF and even some services, like school fees, are also quoted in UF. As suggested later, we consider this period as a suggestive example of Chile's recent experience: monetary policy has not been very effective for influencing the price level, and a key determinant of the decline in inflation has been the appreciation of the real exchange rate.

Exchange-rate policy has been set with the general aim of maintaining the peso within a band that allows fluctuations around an indexed midpoint rate. Currently the band is set to allow depreciations or appreciations of up to 12.5 percent before triggering central bank intervention. 
The midpoint rate is indexed to the productivity-adjusted monthly differential between Chile's CPI inflation and the CPI inflation of Chile's largest trading partners (also through daily adjustments like in the case of the UF). The productivity adjustment is currently set to favor Chile at a rate of 2 percent annually. Intervention within the band has generally been avoided, although it is argued that intervention has been used at times when severe pressure for appreciation of the exchange rate has built up as a result of short-term capital inflows.

It is important to note that the Chilean authorities managed both monetary and exchange rate policies within a flexible setting that allowed them to adjust these policies as necessary in view of new, relevant information and that envisaged a role for supplementary policies. For instance, monetary policy also included close monitoring of the evolution of narrow monetary aggregates by comparing them to predictions of money-demand models, and was supported by a very efficient and strict system of commercial bank supervision. Similarly, exchange rate policy adjusted to allow for widening of the band and step adjustments of the midpoint rate when too much pressure built up in the currency as a result of the surge in capital inflows, and was complemented with policies aimed at weakening inflows of short-term capital by introducing and tightening taxes and timing restrictions on these inflows. The management of the two policies has also reflected the central bank's assessment of the stance of fiscal policy, which is generally kept secret by the fiscal authorities. In this context, assessing the response of the economy to unexpected, exogenous shocks to the central bank's reaction function is particularly important.

The basic indicators that reflect monetary and exchange rate policies are illustrated in Figure 1. This figure plots the 12-month inflation rate, the 90-day rate interest rate in indexed bank loans, and the real effective exchange rate index. The real effective exchange rate index is 
the IMF's measure, according to which a real appreciation is an increase in the index.

\section{(b) Fiscal Policy}

Chile's primary fiscal objective has been to maintain equilibrium in the government sector in the sense of aiming to keep a small surplus in the trend level of the overall fiscal accounts, net of cyclical fluctuations -- particularly those driven by the fluctuations in the world price of copper, which still have an important direct effect on total government revenue and total export revenue. A key instrument in the attainment of this goal has been the Copper Stabilization Fund, which is designed to save a fraction of what are estimated to be windfall gains of temporarily high Copper prices. Just as important has been the Government's strong record of commitment to the rules of this fund, hence avoiding time inconsistency and abstaining from engaging in a fiscal expansion fueled by temporarily higher export receipts.

It is critical to note, however, that significant fiscal distortions still remain in Chile. First, standard measures of the public deficit are misleading because to date the central bank still suffers significant losses as a result of the low-yield assets it acquired as part of the process to rescue the banking system in the mid 1980s, and to some extent also on account of partial sterilization of large capital inflows in the 1990s. Details on the amount of these losses are not publicly available, but it is estimated that they have ranged between 3/4 and 1 percentage points of GDP annually throughout the 1990s. Second, the Ministry of Defense still collects directly $1 / 10$ of the revenue of the government's Copper company, and there is virtually no accountability on the use of these resources. Third, the government still plays a major role on the banking system as owner of the Banco del Estado, one of the country's largest financial institutions.

(c) The External Environment: Copper Prices and Capital Inflows 
Two major developments characterize changes in Chile's external environment during the 1990s: the large and sustained increase in Copper prices and the surge in private capital inflows. To appreciate better the impact of high Copper prices on Chilean production, we focus on Chile's core terms of trade measured as the relative price of Copper to Oil in world commodity markets (given that Chile relies heavily on Oil imports).

The top panel of Figure 2 plots the actual and trend levels of the core terms of trade during the period 1986-1997 at a monthly frequency -- both Copper and Oil prices are taken from the IFS. This chart shows that Chile's successful efforts at stabilizing the economy and attaining high growth in the 1990s coincided with a very large and persistent increase in the relative price of Chile's most important exportable commodity relative to its most critical imported input. The bottom chart provides interesting evidence indicating that this large and persistent rise in Chile's terms of trade is closely related to the country's strong economic performance. The chart plots the 12-month rate of change in the seasonally-adjusted monthly indicator of economic activity (IMACEC) and the 12-month change in the core terms of trade (the latter plotted with a 6-month lag). The evidence from the chart is formalized by running Granger causality tests, which show that the hypothesis that 6 lags of the terms of trade help predict the current IMACEC cannot be rejected at the 5 percent significance level, without any evidence of reversed causality. Moreover, variance decomposition analysis shows that after 2 years about $1 / 4$ of the variability in the growth of IMACEC is attributable to the core terms of trade.

In addition to the direct evidence from the Chilean case, cross-country studies of growth and business cycles in developing economies provide further evidence of the key role that fluctuations in the terms of trade can play both for short-run fluctuations in output and 
expenditures and in long-run growth and saving rates (see Mendoza (1995) and (1997)). In particular, Mendoza (1997) argues that the high volatility of commodity prices can result in high saving and growth rates driven by precautionary saving, in which case the benefits of faster growth can be much less than under normal circumstances. The key role that the terms of trade play in influencing long-run growth is documented also in the work of Easterly et al. (1993), who find that economic policies, educational attainment and political stability contribute little to explain the observed lack of persistence in growth performance, while terms-of-trade changes are highly correlated with growth changes. ${ }^{4}$ Barro and Sala-i-Martin (1995) do find that country characteristics contribute to explain growth differentials, but the terms of trade still play a key role. Their panel regressions show that the growth effects of terms of trade compare to those of educational attainment, public spending on education, human capital, and political instability.

The second key development in Chile's external environment was the surge in capital inflows during the 1990s. This phenomenon has been documented widely for a large group of emerging economies, among others by Calvo et al. (1993), Corbo et al. (1996), and Williamson (1997). There is some debate as to whether these inflows were caused by world phenomena or by the domestic investment climate favored by Chile's stability and structural reforms. However, as Calvo et al. have documented, there is strong statistical evidence indicating that a large fraction of the surge of private capital inflows into emerging economies can be attributed to a temporary decline in industrial country interest rates.

\section{Stabilization Policy and Monetary Transmission}

${ }^{4}$ Pooled regressions in Easterly et al. (1993) show that if the terms of trade gain as a share of GDP rises by 1 percent per annum, annual growth rises by 0.42 percent in the 1970 s and by 0.85 percent in the 1980 s. 
In this section we explore the transmission mechanism of Chilean stabilization policy. We begin with a discussion of the operation of financial indexation under Chile's UF system that identifies a key flaw of conventional discussions of Chilean monetary policy: interest rates quoted as premia over the UF monetary correction factor do not correspond to the real interest rate of the economy. With a clear understanding that the presumed instrument of monetary policy is not the real interest rate -- the macroeconomic effects of which should be easily predictable -- we proceed to develop a statistical framework to assess the connection between the Chilean policy setting described in Section 2 and the performance of the Chilean economy. We, as other authors before us, failed to identify a systematic connection between monetary tightening via increases in UF interest rates and the observed deceleration of inflation, even though the real economy does respond to changes in UF rates. We find, in contrast, that if the monetary policy framework is interpreted instead as being influenced by the evolution of the exchange rate, there is some evidence of a systematic, dynamic connection between the appreciation of real and nominal exchange rates and the fall in inflation. The latter is true in both a conventional unrestricted VAR and in the case of policy shocks to a recursively-identified VAR with a hypothetical policy reaction function for the exchange rate. The statistical analysis begins with a short discussion of technical issues related to identified VAR estimation, and continues later with the policy analysis of the results produced by the VAR.

\section{Chile's Management of Indexed Interest Rates}

As noted earlier, monetary policy in Chile has been conducted throughout the 1990s by influencing the interest rates on indexed financial instruments -- the UF rates. Policy is set to influence most directly an anchor short-term rate (the rate on 90-day promissory notes of the 
central bank until 1995 and from then on the overnight interbank interest rate). Once this key rate is set, the term structure of interest rates on government obligations is market-determined in auctions of longer-term paper. ${ }^{5}$ Thus, through these operations the Bank influences the level of indexed lending and deposit rates at various maturities in the financial system. The value of the anchor interest rate is set to a target estimated to be consistent with objectives for growth and inflation, including since 1995 a publicly-announced inflation target, and monetary aggregates are allowed to adjust accordingly. Consequently, the growth of narrow money has been highly variable over time, as documented below.

The UF is a unit of account that represents an exchange rate between Chilean pesos and an index number linked to CPI inflation with a delay of roughly one month. ${ }^{6}$ Interest on indexed contracts is charged with respect to balances denominated in UF. Because the UF is linked to inflation, the UF interest rate is often viewed as identical to the real interest rate. However, we follow Mendoza (1992) to suggest that this view may be incorrect.

The UF begins to be adjusted in the 10th day of month $t$ by a proportional amount each day, so that by the 9 th day of month $\mathrm{t}+1$ it has increased in value by as much as the CPI did in month $\mathrm{t}-1$. The imperfection of this backward indexation rule is reflected in the fact that the interest rate as quoted in UF and the standard measure of ex post real interest rates are not equivalent, as they would be under perfect indexation (i.e., in a case where the changes in the UF and in the CPI are exactly identical each month). More precisely, there is a differential between

${ }^{5}$ More recently, the Central Bank has aimed to gradually shift the main instrument of policy to nonindexed instruments.

${ }^{6}$ For details on the operation of indexed contracts in Chile and implications for market efficiency between short-run indexed and nonindexed assets see also Mendoza (1992). 
UF interest rates and ex post real interest rates determined by the ratio of the growth observed in both the UF and the CPI between the date an UF-indexed contract is signed and the date it matures -- note that this differential is thus approximately equal to the difference between inflation in the month before a loan is contracted and inflation in the last month of the contract. The differential between ex post real interest rates and UF interest rates at the three-month frequency relevant for monetary policy is illustrated in Figure 3. As the chart shows, imperfect indexation left a significant wedge between ex post real interest rates and UF interest rates, particularly when annual inflation rose or fell, or when monthly inflation fluctuated significantly. In August, 1990, for instance, a 90-day indexed loan charged a quarterly UF rate of about 3 percent, but the ex post rate was in fact near 9 percent.

One could in principle expect that at longer maturities the imperfection of the indexation mechanism could play a smaller role, reflecting a tendency for the wedge between inflation and UF growth to be smaller. However, while it is true that the variability of the indexation error is smaller at 12 than at 3 months (the standard deviation of the former is 1.69 compared to 1.75 for the latter), it is also true that the error does not always fluctuate less with the lengthening of maturity. In fact, the error over 1 month has a smaller standard deviation (0.97) than either the 3or 12-month errors. The 3-month maturity, which is the one relevant for the instrumental rate of monetary policy, displays the largest deviations, on average, from perfect indexation.

The above comparisons between UF and ex post rates may also be questionable because the relevant real interest rates are ex ante rates, which incorporate expectations of inflation. The key expectation agents formulate when assessing 90-day loans in January of any year, for 
example, is a forecast of inflation in April given what is known in January. ${ }^{7}$ Thus, ex ante real interest rates require a three-step ahead forecast of inflation conditional on information available at $t$. One simple model of these expectations of inflation assumes that inflation expected for $t+3$ is simply inflation observed at $\mathrm{t}$. This static rule of thumb has the appealing feature that it yields ex ante real interest rates that correspond, on average, to UF interest rates. ${ }^{8}$ However, there are two arguments that question the relevance of this rule. First, as Mendoza and Fernandez (1994) showed, monthly inflation in Chile has not followed a random walk, as required for this static rule to constitute a rational expectation. Second, the degree of sophistication and inflation-awareness of Chilean financial markets suggest that agents may follow a more rational approach in formulating expectations of inflation than simply expecting it to remain unchanged. ${ }^{9}$ This view is also supported by results of tests of market efficiency and rational expectations applied to interest differentials between indexed and non-indexed deposits by Mendoza (1992).

Since one can view the ex post real interest rate as the ex ante rate of a perfect-foresight economy, and the UF rate as the ex ante rate of a naive economy with static expectations, it is perhaps more realistic to study an ex ante real interest rate based on rational expectations as a middle ground between those two extremes. In this case, the expected value for inflation at date $t+1$, conditional on information available at $t$, must be such that the forecasting error is zero on

${ }^{7}$ Particularly given the inflation observed in December of the previous year, which jointly with the expected inflation for April determines the wedge between the UF interest rate and the true ex ante real interest rate.

${ }^{8}$ Moreover, if the true probabilistic process that governs monthly inflation is a random walk, the difference between the two rates follows a moving average with two lags.

${ }^{9}$ The close attention paid to recurrent "signals" of monthly inflation sent by the Central Bank when agents compare interest rates for the Bank's indexed and nonindexed documents is a clear example of this awareness. 
average and randomly distributed over time. For expectations of inflation at $t+2$ or later, conditional on information available at $t$, the forecasting error of a rational expectation is still zero on average, but may be autocorrelated over time reflecting unknown information emerging between $\mathrm{t}$ and the date for which the rational forecast applies. This is important because, as noted, the ex ante real interest rate at $\mathrm{t}$ of a 90-day indexed asset includes expected inflation for $\mathrm{t}+3$. Thus, in order to construct ex ante real interest rates based on rational expectations, one needs to examine the statistical process that governs monthly inflation and then use this process to compute three-step ahead forecasts.

Mendoza and Fernandez (1994) constructed estimates of rational expectations of inflation for Chile using conventional Box-Jenkins techniques of time-series analysis. They found that monthly inflation follows a fourth-order autoregressive process, with seasonal dummies and two dummies to capture inflationary surges of September and October, 1990, so as to prevent those surges from biasing end-of-sample forecasts. Inflation projections from this model were used to construct a time series of the ex ante real interest rate on 90-365 day loans. The ex ante rate follows a path similar to that of the ex post rate, with the difference between the two being zero on average but displaying some time-dependence due to the nature of the three-step ahead forecast error. Since ex ante and ex post rates differ only by a moving average error, it follows from Figure 3 that the ex ante rate differs significantly from UF rates on a monthly basis. The UF rate is at best a rough approximation to the averages of ex ante and ex post rates -- the approximation is not close because inflation is not a random walk.

In summary, the analysis of the imperfections embodied in the UF indexation mechanism implies that monetary policy implemented by influencing UF interest rates cannot be interpreted as 
influencing the real interest rate, either in ex post or ex ante terms. By targeting UF interest rates the monetary authority is likely to influence real interest rates depending on how actual or expected inflation react to UF interest rate targets, but this is not substantially different from what occurs in the usual environment of nominal interest rates -- in fact, we show below in a basic theoretical model with staggered prices that price dynamics in the face of fully-anticipated policy changes are exactly the same under UF indexation than under no indexation. Moreover, given the evidence on the variability of the differential between UF interest rates and ex post real interest rates, one can infer that the monetary authority may also introduce unpredictable noise in real interest rates when inducing unanticipated changes in UF interest rates.

\section{Identified VAR Estimation of a Chilean Model of Monetary Policy}

We summarize the discussion of the recursive identification approach to Identified VAR policy models following Christiano, Eichembaum and Evans (1997). The basic assumption of this analysis is that the policy instrument is governed by the following reaction function:

$$
r_{t}=f\left(\Omega_{t}\right)+\sigma \epsilon_{t}
$$

This specification of the reaction function embodies the following assumptions: $S_{t}$ is the information set containing the variables known by the authorities when choosing the value of $r_{t}, f$ is a linear function that describes the systematic reaction of the central bank to changes in the economic environment as reflected in indicators included in the information set, and, is a unitvariance exogenous policy shock. In this approach, $f$ is a function that embodies the central bank's strategy to conduct stabilization policy, including issues about priorities of various policy goals and preferences regarding inflation rates, exchange rates, and other variables. In contrast, 
the shock ${ }_{t}$ captures any nonsystematic factors that could affect policy decisions (political factors, subjective views of policy makers, changes in central bank staff, assessments of the unknown stance of fiscal policy, measurement error in the policy instrument, and any other unexpected exogenous shocks).

The recursive identification strategy differs from other identification approaches (such as those advocated by Sims and Zha (1995)) in that it follows a straightforward method to isolate exogenous innovations to the policy reaction function. Recursive identification assumes that $S_{t}$ includes lagged values of the relevant variables, as in an unrestricted VAR, plus certain contemporaneous variables. The contemporaneous variables in $\mathrm{S}_{\mathrm{t}}$ include any variable that does not respond contemporaneously to the policy shock, while variables which do not enter contemporaneously in $\mathrm{S}_{\mathrm{t}}$ are those that do respond at date $\mathrm{t}$ to date-t policy shocks. As a result, policy shocks are by construction orthogonal to the other right-hand-side variables in the policy reaction function, and hence can be recovered directly as the residual from an OLS regression. ${ }^{10}$ Thus, conditional on the specification of the policy reaction function, the dynamic response of any variable to a policy shock is measured by the regression coefficients of that variable on current and lagged values of , . This is asymptotically equivalent to computing the impulse response function of a variable to an innovation in, using a VAR model in which the policy reaction function enters "identified" by the right-hand-side contemporaneous variables.

Two important remarks regarding recursively-identified VAR estimation. First, note that, as Evans and Marshall (1997) showed, a general reaction function like the one specified above

${ }^{10}$ Sims and Zha (1995) used an alternative strategy that identifies the policy reaction function by imposing nonrecursive identification restrictions either in the matrix of autocorrelation of the VAR's errors or on the covariance structure of innovations. 
can capture in reduced form reaction functions that incorporate inflation targets, such as the wellknown Taylor Rule (see Taylor, 1993) relating the policy instrument to the output gap and conditional expected inflation in linear fashion. Second, recursively-identified estimation does not require an explicit and complete structural model of the macroeconomy. What it requires is identification of (a) those variables that are endogenous and those that are exogenous, (b) those that enter in the information set of the monetary authority at the moment of setting policy, and (c) the subset of the variables in the information set of the central bank that responds contemporaneously to policy changes. Once these identifying assumptions are made, the dynamic relationship across the variables is data-determined through VAR estimation. Clearly, considerations of theory, practical knowledge of the policy environment, and statistical limitations play a key role in the identifying assumptions. As a result, the reaction function can only be specified at best as an approximation. Christiano et al. (1997) describe the ongoing debate in the case of the United States over the choice of the relevant right-hand-side variable of the policy reaction function and the set of variables (and their timing) in the left-hand-side. Recursively-Identified VAR Models for Chilean Stabilization Policy

We examine first a benchmark recursively-identified VAR model of Chilean stabilization policy in which the reaction function is defined using the 90-day indexed lending rate (R90) as the policy instrument. The right-hand-side variables are logarithms of the consumer price index $(\mathrm{P})$, the IMF's measure of the real effective exchange rate (RER), the seasonally-adjusted monthly index of economic activity (IMACEC), the adjusted measure of narrow money supply (M1A), the stock of net international reserves (NIR), and the core terms of trade (TOT). We used monthly data for the period January, 1986-May, 1997 obtained from various issues of the Monthly Bulletin 
of the Central Bank of Chile and from the IFS. To balance the trade off between minimizing omitted variable bias and the loss of degrees of freedom that multiplies as the variables added to the VAR increase, ${ }^{11}$ we followed the same practice of Christiano et al. (1997) and Evans and Marshall (1997) and restricted estimation to include only 6 lags of each variable -- thus, the usable observations actually entering into the VAR start in January, 1987. Robustness of this restriction was tested using conventional tests such as Q and AIC (Akaike Information Criterion) statistics.

The variables that we consider to be unaffected on date $t$ by a date-t policy innovation to R90 are P, IMACEC, RER and TOT, and the variables that are allowed to adjust immediately to the R90 shock are M1A and NIR. These settings are consistent with the view that prices and output respond with at least a delay of one month to policy innovations. Since RER is in some sense targeted too, because of the indexation rule on the nominal exchange rate, assuming that $\mathrm{P}$ is "sticky" forces the assumption that RER must also be "sticky." The assumption that TOT is unaffected by a date-t policy shock simply reflects the view that Chile is a small open economy, and hence the world relative price of Copper in terms of Oil is exogenous to developments within Chile. M1A and NIR are assumed to respond immediately to policy innovations reflecting the Chilean policy that allows money supply to adjust without intervention to interest-rate changes, and the limited effectiveness of sterilized intervention in an economy as open to trade and capital flows as Chile. Note in addition that one can also view the variables we introduced in the reaction function as conveying information regarding other important variables that the monetary authority in Chile did consider to be critical, such as the current account, the growth of private

\footnotetext{
${ }^{11}$ If we include $k$ lags and $n$ variables in the VAR, estimation requires $k \times n^{2}$ free parameters.
} 
expenditures, or labor market indicators -- these can be interpreted as functions of the variables we included, which have the advantage of being available at a monthly frequency and with very short reporting lags, and hence the notion of (1) as a "reduced form" relationship.

The analysis of the model's impulse response functions in the presence of a 1-standarddeviation to the policy innovation (Figure 4) show a striking result. ${ }^{12}$ The response of all macroeconomic variables to the policy innovation is in line with economic intuition, with the major exception that an increase in the indexed interest rate leads to a persistent increase in the price level. That is, a rise in R90, far from reducing inflation, results in a temporary surge in inflation and leaves the price level permanently higher. This despite temporary declines in IMACEC and M1A, and a permanent increase in foreign reserves. Notice also that the R90 innovation hardly affects the real exchange rate, so implicit in these impulse response functions are adjustments of the nominal exchange rate (including both adjustments within the band and adjustments of the band) in response to the increase in $\mathrm{P}$ that work to maintain RER constant. ${ }^{13}$

The analysis of the restricted VAR helps us identify the effects of exogenous monetary policy innovations, but it does not help us gauge the contribution of the endogenous systematic response of the policy instrument to changes in its determinants. Thus, one could argue that Chilean policy instrumented via R90 was an effective tool because of the way it reacted to

\footnotetext{
${ }^{12}$ The impulse response functions are plotted together with \pm 2 standard error bands calculated via Monte Carlo simulations using 100 repetitions.

${ }^{13}$ These results are robust to whether only the price of Copper instead of TOT is used in the estimation, and to whether commodity prices enter or not in the analysis. Thus, unlike in the case of applications of restricted VAR techniques for the U.S. economy (see Christiano et al. (1997)), the so-called "price puzzle" remains in the Chilean case despite the introduction of commodity prices.
} 
changes in the right-hand-side variables of (1), and hence there was still an important contribution of monetary policy to the decline in inflation. As Christiano et al. (1997) explain, the analysis of the systematic component of the policy reaction function is a difficult task that cannot be disentangled in general from the classic problem of interpretation of the degree of exogeneity that goes into the ordering of variables in the Choleski decomposition of a VAR. However, in the framework presented here one can shed some light on this issue by asking simply whether positive innovations to R90, due to exogenous policy shocks or to systematic responses to changes in other endogenous variables, result in declines in the inflation rate or the price level. As Figure 5 clearly illustrates, the price level still increases and remains permanently higher in the impulse response function to a 1-percent shock to R90 of an unrestricted VAR.

We acknowledge that we are not the first authors concerned with understanding the mechanism of monetary transmission in Chile, and troubled by the puzzling implications of the data when the setting of monetary policy is modeled to capture the conventional wisdom presented in Section 2. The above results resemble those of other authors obtained using unrestricted VAR estimates and Granger causality tests (e.g., Mendoza and Fernandez (1994), Rojas (1993), and Rosende and Herrera (1991)). More recently, Morande and Schmidt-Hebbel (1997) and Valdes (1997) experimented with nonrecursively-identified VARs and obtained results very analogous to the ones we found. These studies differ, however, in that they also estimated VAR specifications in which interest rate innovations did show some evidence of reducing the gap between actual inflation and the announced inflation target (both measured in terms of a redefined "core" CPI). This is an interesting finding but we were unable to make it consistent with the methodology we followed for two reasons. First, as Evans and Marshall (1997) suggest, 
inflation targeting does not produce a recursively-identified VAR setting in which the inflation gap can be treated as a dependent variable. Instead, it implies that the reaction function must include the variables on which the monetary authority conditions its inflation target -- which is analogous to the procedure we followed. Second, from a theoretical standpoint, introducing the inflation gap in the VAR presents nontrivial difficulties with the notion of a rational-expectations equilibrium. For example, in a hypothetical case in which a fully credible target were set monthly, rational expectations imply that the inflation gap is a white noise error, and there would be no systematic link between this gap and interest rate innovations.

The aim of these VAR experiments was to assess the operating hypothesis of the conventional wisdom regarding Chilean monetary policy: monetary policy manages real interest rates by influencing UF rates with the aim of reducing inflation via adjustments in the growth of output and expenditures. This view also considers lags in the monetary transmission mechanism that could cause the decline of inflation to be slow and erratic. However, the fact that R90 does not correspond to Chile's real interest rate, the evidence of our restricted and unrestricted VARs, and the evidence from most of the other studies cited above, seem to cast some doubt on the existence of systematic linkages to support the conventional wisdom on Chilean monetary policy.

The puzzling positive effect of increases in R90 on the Chilean price level is clearly fleshed out by the experience of the Sobreajuste period mentioned earlier. The large increase in the UF lending rate -- characterized by a rise in the UF rate from about 7-8 percent to near 16 percent that started in 1989 and peaked in early 1990 -- was followed with some delay by a decline in economic activity. There was also a deceleration in money growth that was closer in time to the tightening of monetary policy -- by the end of 1990 the growth of M1A had fallen from near 40 
percent in January 1989 to about 10 percent. However, for several months after the increase in R90 reached its maximum, inflation continued to increase and even accelerated, until it began to decline in 1991. Inflation did not return to the level it had before the tightening began in 1989 until December of 1992. The idea that the real interest rate could increase as one would believe it did during this period (if one accepted the notion that UF rates are real interest rates) is very hard to reconcile with the observed resilience of the inflation rate and the widely-accepted view that Chile is a well-functioning market economy.

\section{An Alternative View: Chile's Price Puzzle and a Reaction Function for the Exchange Rate}

The puzzling result that the response of the price level to tighter monetary policy can be the opposite to what is expected by the monetary authority is not unique to the Chilean case. This so-called price puzzle is well-known in the literature that examines VAR models of U.S. monetary policy (see the survey by Christiano et al. (1997)). This literature has shown that in the case of the United States the puzzle is resolved by introducing commodity prices in the information set of the monetary authority that enters in the reaction function. This, however, is not the case in our VARs for Chile. Still, the interpretation of the price puzzle given in the American literature provides a very appealing intuition for what might be affecting the analysis of the Chilean case: "the conjecture is that policy shocks which are associated with substantial price puzzles are actually confounded with nonpolicy disturbances that signal future increases in prices" (Christiano et al. (1997), p. 36). ${ }^{14}$

In this section we propose one alternative for resolving Chile's price puzzle that specifies a

\footnotetext{
${ }^{14}$ Roberto Zahler provided us with an account of the aftermath of the Sobreajuste that can be nicely interpreted from this perspective.
} 
policy reaction function in which the exchange rate is viewed as the dependent variable. This approach is motivated by our previous casual observation (e.g., Figure 1) that the gradual decline of Chilean inflation in the 1990s was associated with the real appreciation of the currency, and by our discussion of Chilean stabilization policy in Section 2 -- in which we noted the flexibility of the exchange-rate arrangement and the concerns for the real value of the currency and the size of the current account deficit. Note, however, that this reaction function for the exchange rate is largely hypothetical. There is no written evidence of an explicit strategy for influencing the exchange rate, and hence the argument is based on anecdotal evidence of interventions within the exchange-rate band and on the recurrent step adjustments to the width of the band and the formula for calculating the midpoint.

We examine first the unrestricted VAR estimated above to obtain impulse response functions to a 1-percent standard deviation shock to the real exchange rate (see Figure 6). A shock that appreciates the real exchange rate can account for the permanent decline in the Chilean price level and a persistent increase in output, with temporary fluctuations in interest rates and the quantity of money. Note, however, that a zero-to-slightly-positive response of the price level to the real appreciation remains within the 95-percent confidence interval, so formally the price puzzle is not fully resolved. Still, the position of the point estimates of the impulse response function of the price level relative to the bounds of the confidence interval suggests that, on average, the price level is most likely to fall as the real exchange rate appreciates -- for an analogous discussion of impulse responses of the price level and their corresponding confidence intervals see Christiano et al. (1997) p. 36.

We consider next a framework of a recursively-identified VAR in which the policy 
reaction function is expressed in terms of the nominal exchange rate, E, in pesos per U.S. dollar, as the instrument of policy. In this framework we maintain that IMACEC and TOT are independent of current policy innovations, but we allow the consumer price index $(\mathrm{P})$ to respond to contemporaneous innovations in the exchange rate. This assumption is consistent with the views that (a) there was an explicit policy to target the real exchange rate embodied in the rule that indexed the mid-point of the band to the lagged productivity-adjusted international inflation differential, and (b) while prices of nontradable goods can be relatively sticky, at least at a monthly frequency, $\mathrm{P}$ moves together with $\mathrm{E}$ because the price of imports in domestic currency moves together with the exchange rate. Thus, we wish to capture in the policy innovations to $\mathrm{E}$ any dynamic effects that go beyond the mechanical effects of changes in the exchange rate on the prices of traded goods. M1A, R90 and NIR are also modelled as variables that can react contemporaneously to nominal exchange rate shocks.

Impulse response functions for this alternative policy scenario are plotted in Figure 7. Note that in this case an increase in $\mathrm{E}$ is a depreciation, in contrast to an increase in RER that constituted an appreciation in Figure 6. Clearly, judging from the point estimates of the impulse response functions, a policy shock that results in a nominal depreciation equal to a 1-percent standard deviation in E leads to a permanent upward adjustment in the price level, a persistent fall in output, and temporary fluctuations of foreign reserves, the quantity of money, and the indexed 90-day interest rate. ${ }^{15}$ As before, however, when the confidence intervals are considered the results are less robust and cannot reject the hypothesis that the responses of all variables may be

\footnotetext{
${ }^{15}$ The persistent output decline in response to a nominal devaluation represents another puzzle that deserves further examination.
} 
insignificantly different from zero at the 95-percent confidence level.

The impulse response functions to the identified shock to exchange rate policy suggest that the observed appreciation of the Chilean peso might have played a role in explaining the reduction in the rate of inflation. Thus, it might be possible to resolve the price puzzle presented by the analysis of the UF interest rate as the instrument of policy if we re-interpret the Chilean policy setting as one in which stabilization efforts were concerned mainly with the evolution of the external sector, particularly the exchange rate. This, however, still leaves us with important unanswered questions. In particular, we do not know to what extent it was the systematic response of E (implicitly through the indexation rule of the mid-point of the band and the marketdetermined fluctuations around it) to the endogenous adjustment of the economy to terms-oftrade gains and capital inflows responsible for the stabilization of the economy, and we do not study here whether the latter can be attributed to Chilean policy or to exogenous shocks. Interpreting the Dynamics of the Chilean Economy: Staggered Prices under Indexation

In what follows we interpret the Chilean experience in the light of the predictions of a basic model with a staggered-price setting mechanism in an environment of imperfect indexation similar to the one corresponding to the UF system. We show that the same reduced-form equation establishing an inverse relationship between the change in the rate of inflation over time and excess demand derived in Calvo (1983), using a rational-expectations model without indexation, holds in the case of UF indexation. This inverse relationship also embodies a policy similar to the one followed to adjust the mid-point of the exchange rate band.

Let $x_{t}$ denote the difference between the price set by firms which are setting the price at time $t$ and the UF along the length of the contract. Thus, if the contract lasts until time $s>t$, then 
the price set by the firm at time $s$ would be $\mathrm{UF}_{s}+x_{t}$. We postulate:

$$
x_{t}=\delta \int_{t}^{\infty}\left(P_{s}-U_{s}+Z_{s}\right) e^{-\delta(s-t)} d s,
$$

where ${ }^{*}, P, U$, and $Z$ denote the inverse of the average contract length, the $(\log )$ of the price level, (log of) the UF, and excess demand, respectively.

Therefore, differentiating equation (2) with respect to time, we get:

$$
\dot{x}_{t}=\delta\left(x_{t}+U_{t}-Z_{t}\right) \text {. }
$$

On the other hand, the price level satisfies:

$$
P_{t}=\delta \int_{-\infty}^{t}\left(x_{s}+U_{t}\right) e^{-\delta(t-s)} d s
$$

Thus, differentiating equation (4) with respect to time, we get:

$$
\dot{P}_{t}=\delta\left(x_{t}+U_{t}-P_{t}\right)
$$

Consequently, denoting $\pi=\dot{P}$, from equations (3) and (5), we have:

$$
\dot{\pi}_{t}=-\delta^{2} Z_{t},
$$

which is the same expression of Calvo (1983) for a nonindexed economy. This reduced-form, perfect-foresight representation of inflation dynamics seems to be roughly in line with the Chilean experience, where the fall (increase) of inflation during the 1990s coincided with the acceleration 
(deceleration) of economic activity. This comparison is of limited relevance, however, since (6) is a perfect-foresight prediction that holds for fully-anticipated policy changes.

The above result also implies that, in a rational expectations world, indexation with the UF system has no effect on price dynamics. Indexation could, however, have an effect on the level of inflation and uniqueness of monetary equilibrium. For example, let us assume that

$$
Z_{t}=-b p_{t}, \quad b>0
$$

where $p=P-E$, and $E=\log$ of nominal exchange rate. Thus, assuming the international price level constant, $p$ is the (log of the) real exchange rate (as computed by the IMF). Hence,

$$
\dot{p}_{t}=\pi_{t}-\varepsilon_{t}
$$

where, stands for the rate of devaluation.

Consider now the case in which the rate of devaluation is indexed to some lagged rate of inflation (as in Chile), such that:

$$
\begin{gathered}
\dot{\varepsilon}_{t}=\gamma\left(\pi_{t}-\varepsilon_{t}\right) \\
\dot{P}=\delta x_{t}=\delta\left(P_{t}-U_{t}+Z_{t}\right) .
\end{gathered}
$$

By (8) and (9), it follows that

$$
\varepsilon_{t}=\gamma\left(p_{t}-p_{0}\right)+\varepsilon_{0}
$$

Using equation (10) in (8), we get:

$$
\dot{p}_{t}=\pi_{t}-\varepsilon_{0}-\gamma\left(p_{t}-p_{0}\right) .
$$


At steady state, $\dot{p}=p=0$. Thus,

$$
\pi_{\infty}=\varepsilon_{0}+\gamma p_{0}
$$

where the subindex 4 denotes 'steady state.' An implication of equation (13) is that the steady state rate of inflation is a function of initial conditions. In particular, the more appreciated is the currency in real terms with respect to steady state initially, the higher is steady state inflation.

\section{Concluding Remarks}

Our assessment of the Chilean macroeconomic policy setting of the 1990s shows that it is difficult to assign a very important role to interest-rate or exchange-rate policies per se in the notable accomplishments of the Chilean economy. One important conjecture in this assessment was the argument that unusually favorable terms of trade and the surge in capital inflows have been important elements in the Chilean success. In as much as this is true, one can argue that the Chilean economy has not been 'tried by fire' because ever since Chile took the high-growth track, the economy has not faced large adverse exogenous shocks ${ }^{16}$ or even fallen into recession.

It should be noted, however, that failure to find a systematic link between monetary policy and inflation is not an indictment of Chilean macroeconomic policy. First, weak and even paradoxical links of that sort have also been found for the U.S. economy (Christiano et al (1997)), even though one must acknowledge that in Chile's case the "price puzzle" has proven more robust and is yet to be resolved. Second, our analysis has not examined the impact of other key policies

${ }^{16}$ This situation has started to change after the recent Asian crises which has brought about a sharp fall in Copper prices. This will give us a chance to test the resilience of the Chilean economy to adverse terms of trade. 
that are hard to quantify as, for instance, sound and efficient bank supervision and lengthening the maturity structure of public debt.

Nevertheless, our analysis sheds some doubts on the effectiveness of interest rate policy as an antiinflationary device, and suggests that some degree of exchange rate anchoring could at the very least help to rein in the dreaded beast. These findings, particularly the first one, echo a view that is predominant in the economics profession, as represented by the quotation from Robert Lucas at the beginning of the paper.

Countries contemplating the use of the interest rate as a stabilization device should also be aware of the fact that taxation of capital inflows is a central policy instrument in Chile. The latter helped to insulate domestic interest rates from international ones and, thus, enhance the effectiveness of monetary policy. However, a possible problem with capital inflow taxes is that, as a result, domestic interest rates may substantially exceed international interest rates, inducing the development of tax-evasion loopholes. Moreover, as loopholes grow, domestic residents incur in foreign-exchange-denominated borrowing, which implies a virtual 'dollarization' of the economy, and increases the economy's vulnerability to currency devaluation -- as recently shown in Indonesia and Korea. ${ }^{17}$

${ }^{17}$ To all accounts, Chile is mostly free from this problem because of strict controls. 


\section{References}

Calvo, Guillermo, A, (1983), "Staggered Prices in a Utility-Maximizing Framework," Journal of Monetary Economics, v. 12, pp. 383-98.

, Leonardo Leiderman and Carmen M. Reinhart, (1993), "Capital Inflows and Real

Exchange Rate Appreciation in Latin America," IMF Staff Papers, v 40, pp.108-151.

Christiano, Lawrence J., Martin Eichembaum and Charles L. Evans, (1997) "Monetary Policy Shocks: What Have We Learned and to What End?," forthcoming, Handbook of Macroeconomics, North-Holland Pub. Co.

Corbo, Vittorio, Rolf Ludders, and Pablo Spiller (1996), "The Foundations of Successful Economic Reforms: The Case of Chile," mimeo, Catholic University of Chile, Santiago.

Dornbusch, Rudiger, Ilan Goldjfan, and Rodrigo P. Valdes, (1995), "Currency Crises and Collapses," Brookings Papers on Economic Activity, 2:1995.

Evans, Charles L. and David A. Marshall, (1997) "Monetary Policy and the Terms Structure of Nominal Interest Rates," mimeo, Federal Reserve Bank of Chicago.

Mendoza, Enrique G. (1992), "Fisherian Transmission and Efficient Arbitrage under Partial Financial Indexation: The Case of Chile," IMF Staff Papers, 39, no. 1.

(1995), "The Terms of Trade, the Real Exchange Rate, and Economic Fluctuations," International Economic Review, February 1995.

, (1997), "Terms-of-Trade Uncertainty and Economic Growth: Are Risk Indicators Significant in Growth Regressions," forthcoming, Journal of Development Economics.

and F. Fernandez, (1994), "Monetary Transmission and Financial Indexation: Evidence from the Chilean Economy," PPAA No. 94/17, International Monetary Fund, Washington D.C.

Morande, Felipe and Klaus Schmidt-Hebbel (1997), "Inflation Targets and Indexation in Chile," mimeo, Central Bank of Chile.

Rojas, Patricio, "El Dinero como un Objetivo Intermedio de la Politica Monetaria en Chile," Cuadernos de Economia 30, no. 90, pp. 139-178, Agosto 1993.

Rosende, Francisco and L. O. Herrera, "Teoria y Politica Monetaria: Elementos para el Analisis," Cuadernos de Economia no. 83, Abril 1991. 
Sims, Christopher A. (1992), "Interpreting the Macroeconomic Time Series Facts: The Effects of Monetary Policy," European Economic Review, vol. 36, No. 5, pp. 975-1000 and Tao Zha, (1995), "Does Monetary Policy Generate Recessions," mimeo, Department of Economic, Yale University.

Taylor, John, (1993), "Discretion versus Policy Rules in Practice," Carnegie-Rochester Conference Series on Public Policy, v. 39, pp. 195-214.

Valdes, Rodrigo P., (1997), "Transmision de la Politica Monetaria en Chile," mimeo, Banco Central de Chile.

Williamson, John, (1997), "Mexican Policy Toward Foreign Borrowing," in Coming Together: US-Mexico Relations, B. Bosworth, S. Collins and N. Lustig eds., Brookings Institution, Washington. DC. 
Figure1.

Chile: Inflation, Interest Rate and Real Exchange Rate

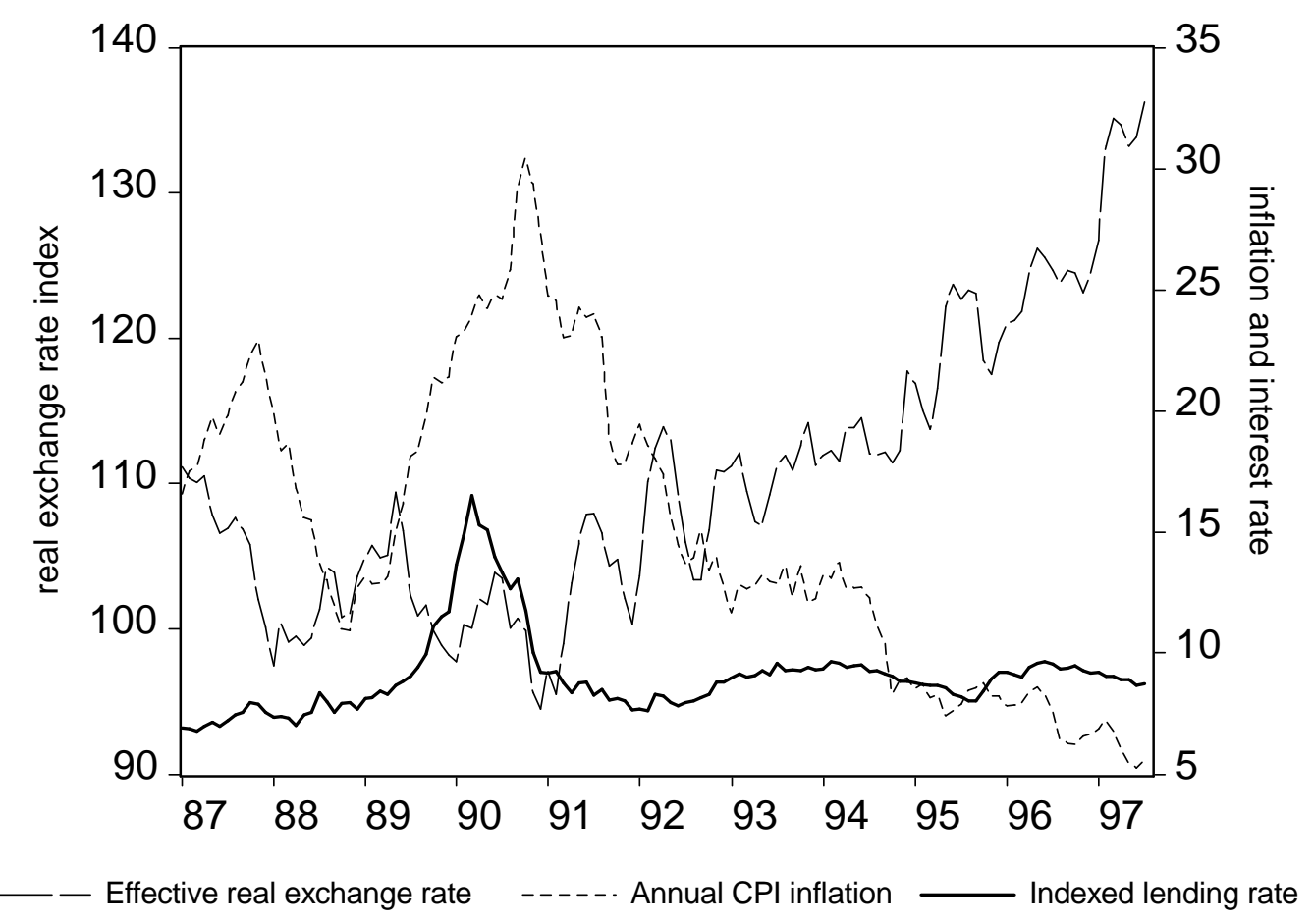


Figure 2.

Chile: Economic A od uty and the Core Terms of Trade
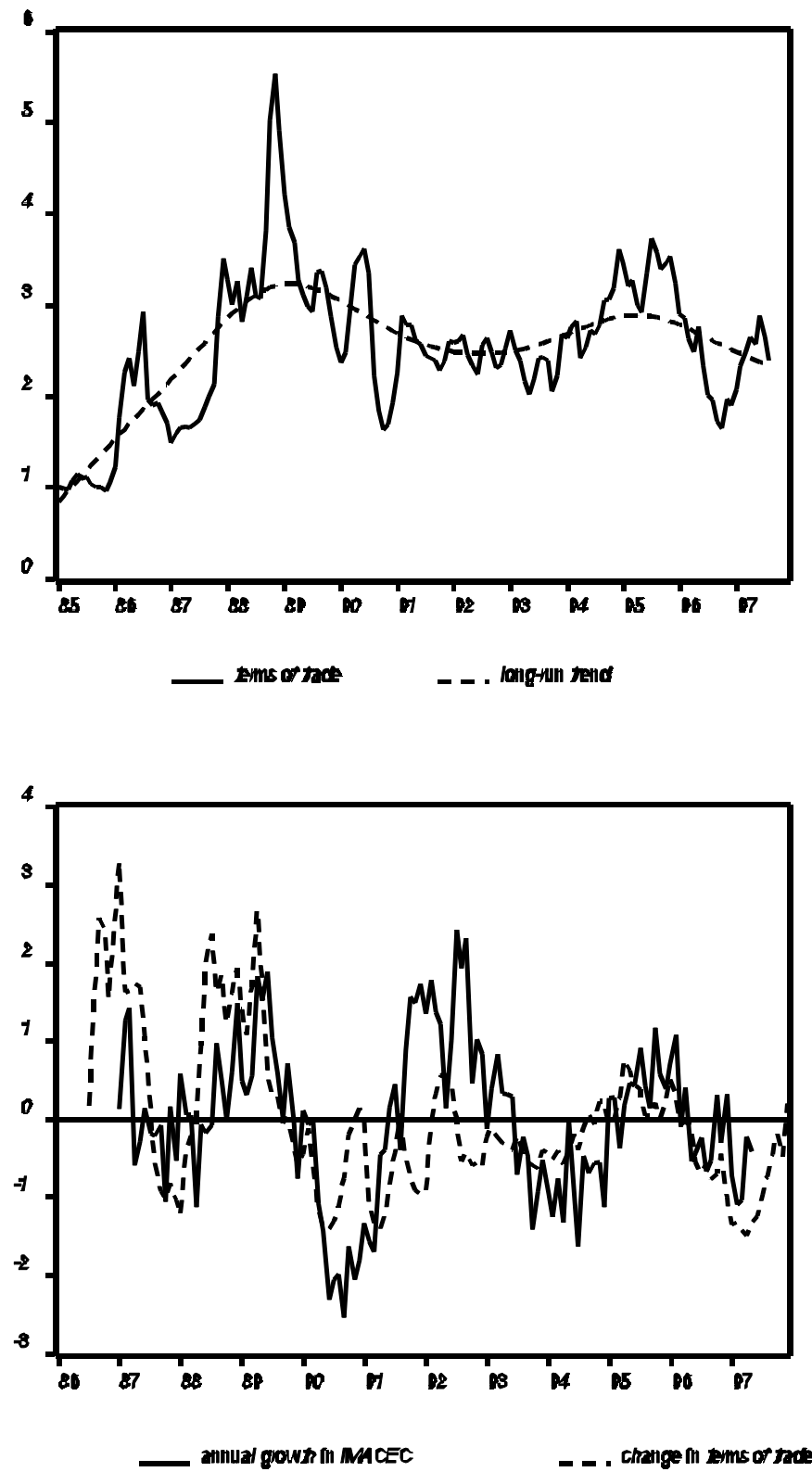

Not: The tems of tach are measunedas the pice of copperili tems of ol in wold maket. MACECIS the seasonallyadustedmonthly findCabr of economic acfily, The change fil ems

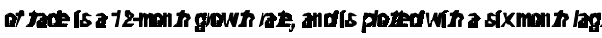


Fgure 3.

\section{Chle: Dillerentid between UFInterest Rates and Inflation}

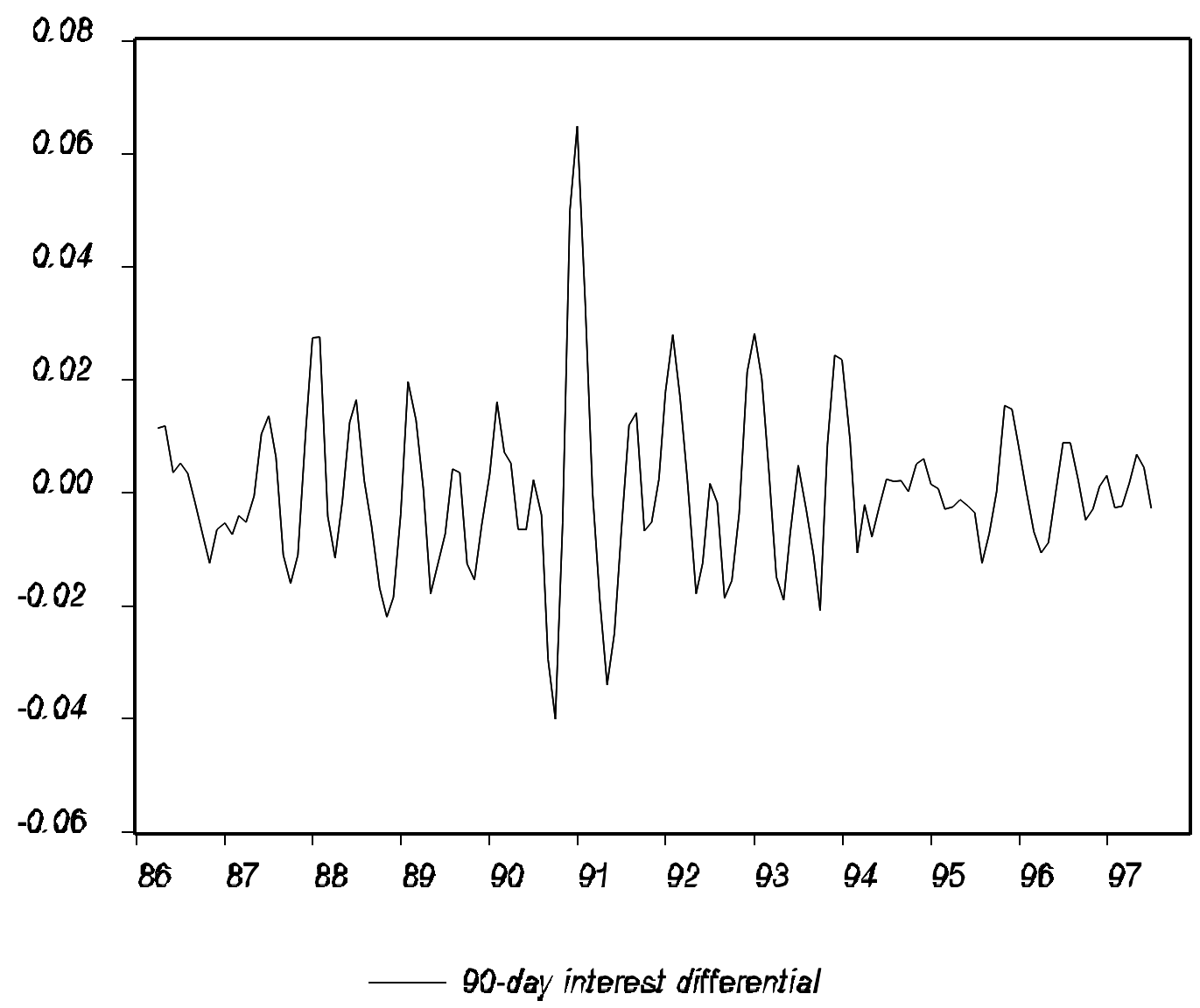

Note: Quarterly differential between interest rates quoted in UF and ex-post real interest rates computed as $L n[(U F t+3 / U F t) *(C P / t / C P / t+3)]$. 
Figure 4.

Response to One S.D. Innovation in the UF Lending Rate (model with the relative price of Copper in terms of Oil)

Response of RSHOCK to RSHOCK

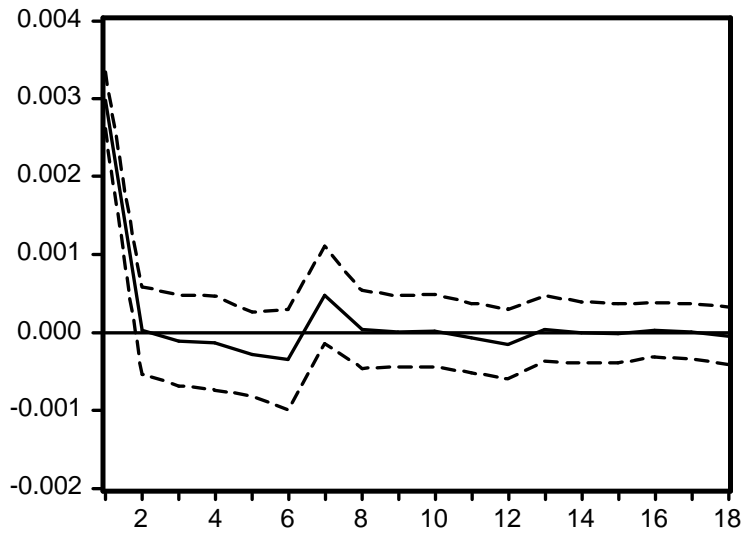

Response of LY to RSHOCK

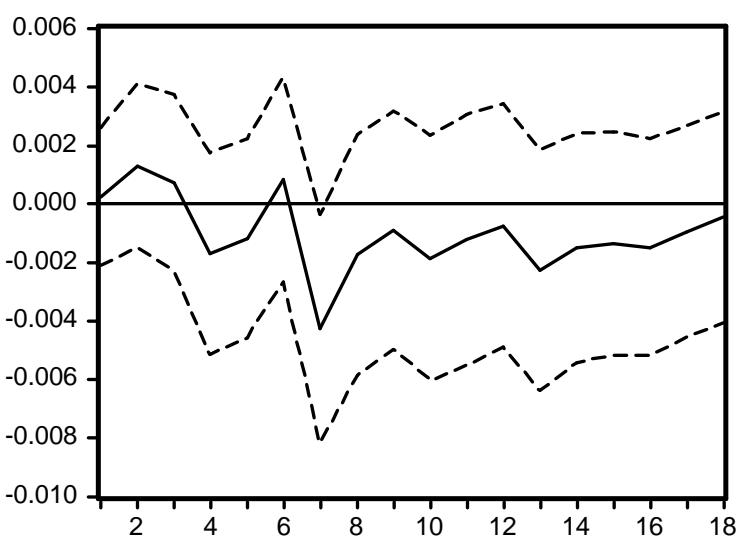

Response of LM1A to RSHOCK

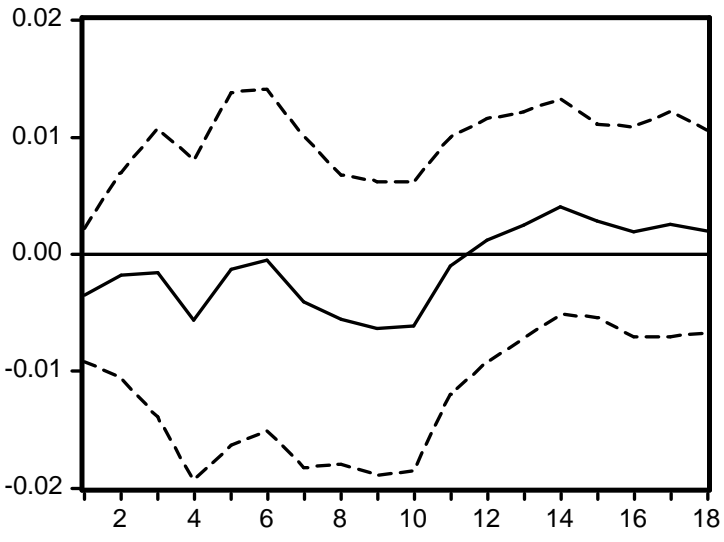

Response of LP to RSHOCK

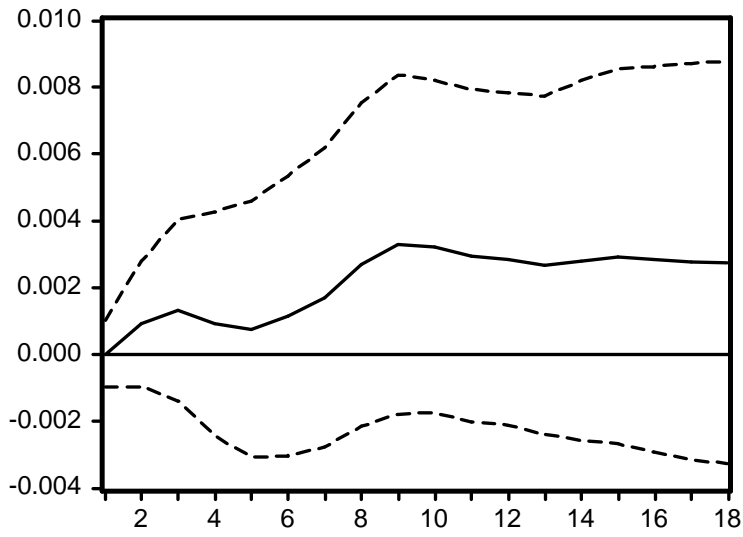

Response of LRER to RSHOCK

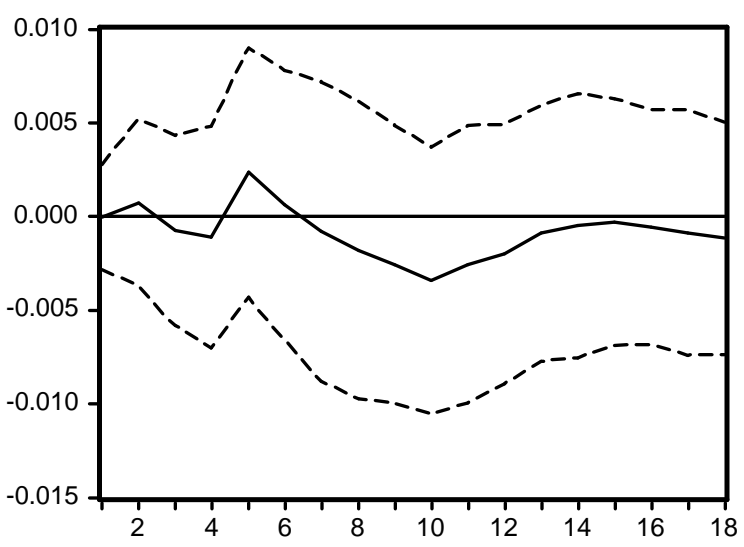

Response of LNIR to RSHOCK

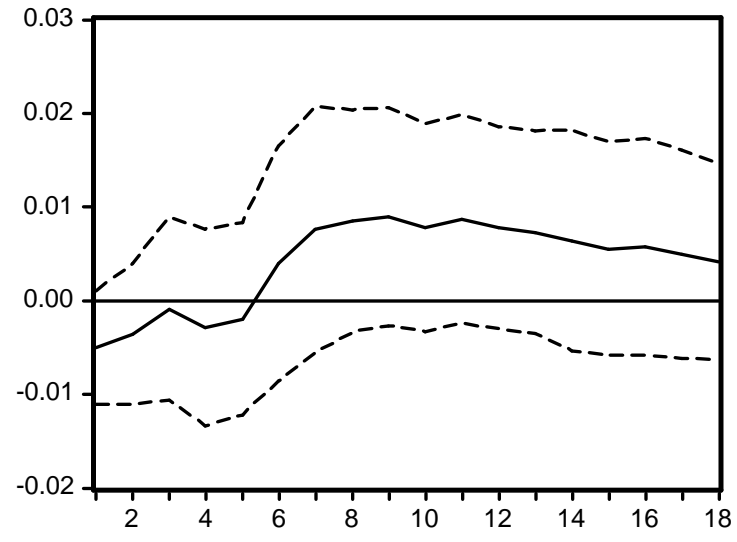


Figure 5.

Response to One $S . Q$ mnovation in $U F$ Lending Rate

(unrestricted VAR with copper price as exoyenous variable)
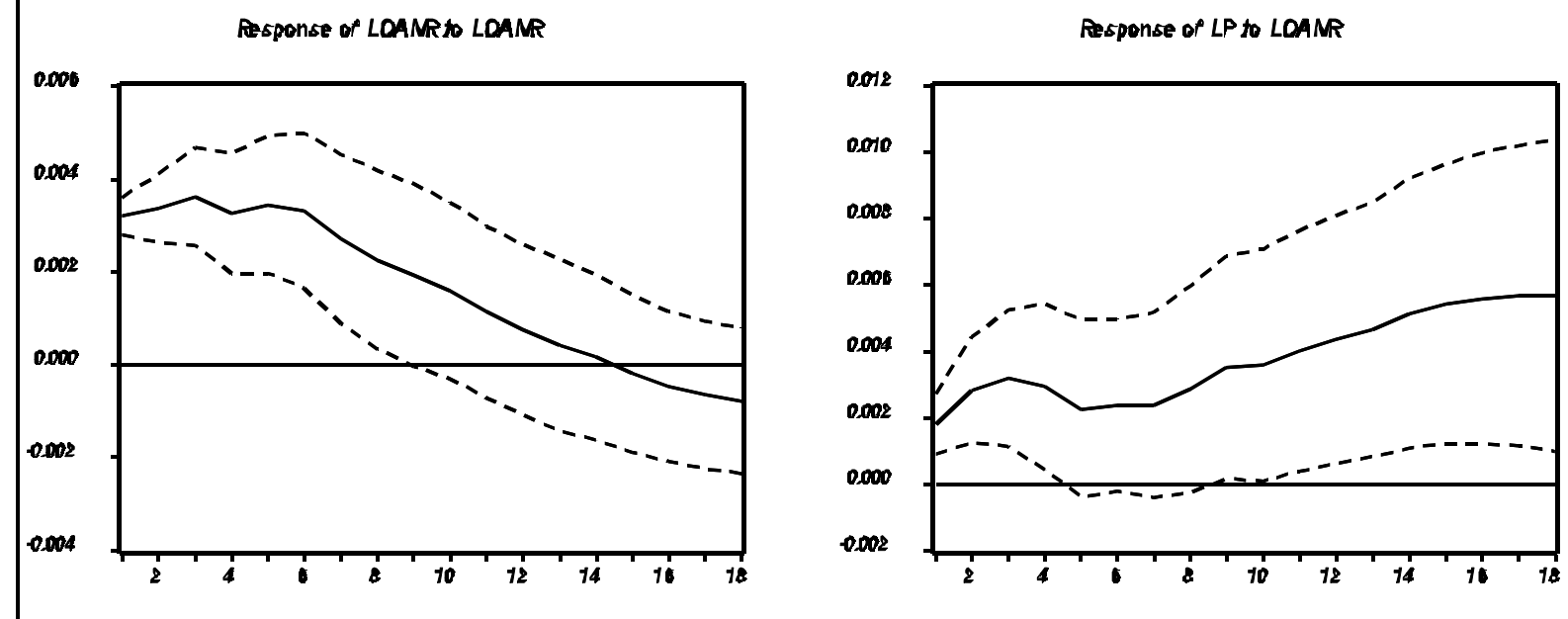

Aespense of LY to LOAMR

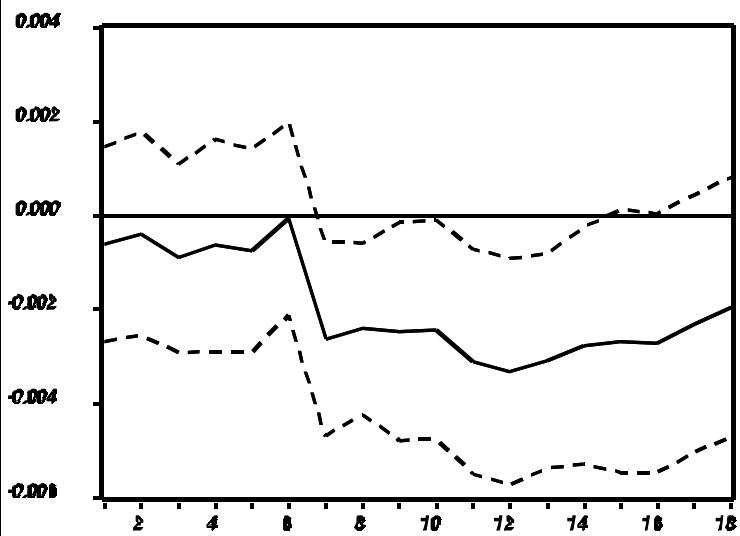

Response of LRERto LOAMR

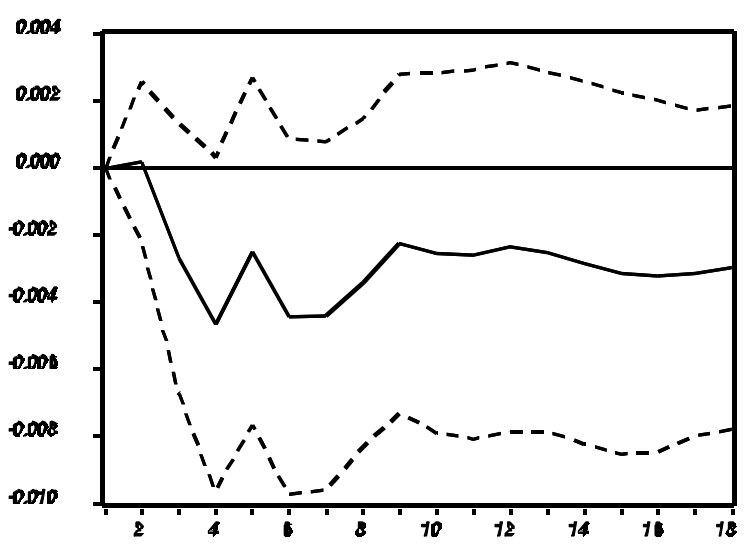

Response of LMIA to LOAMR
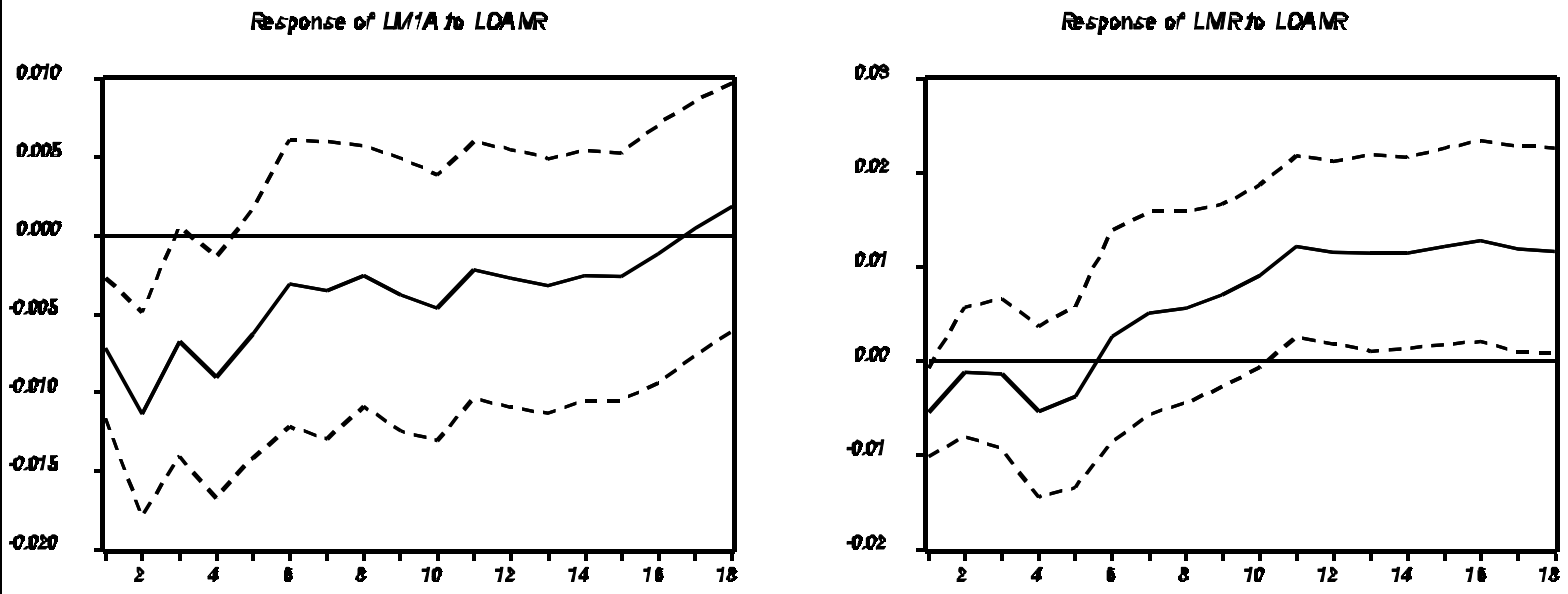


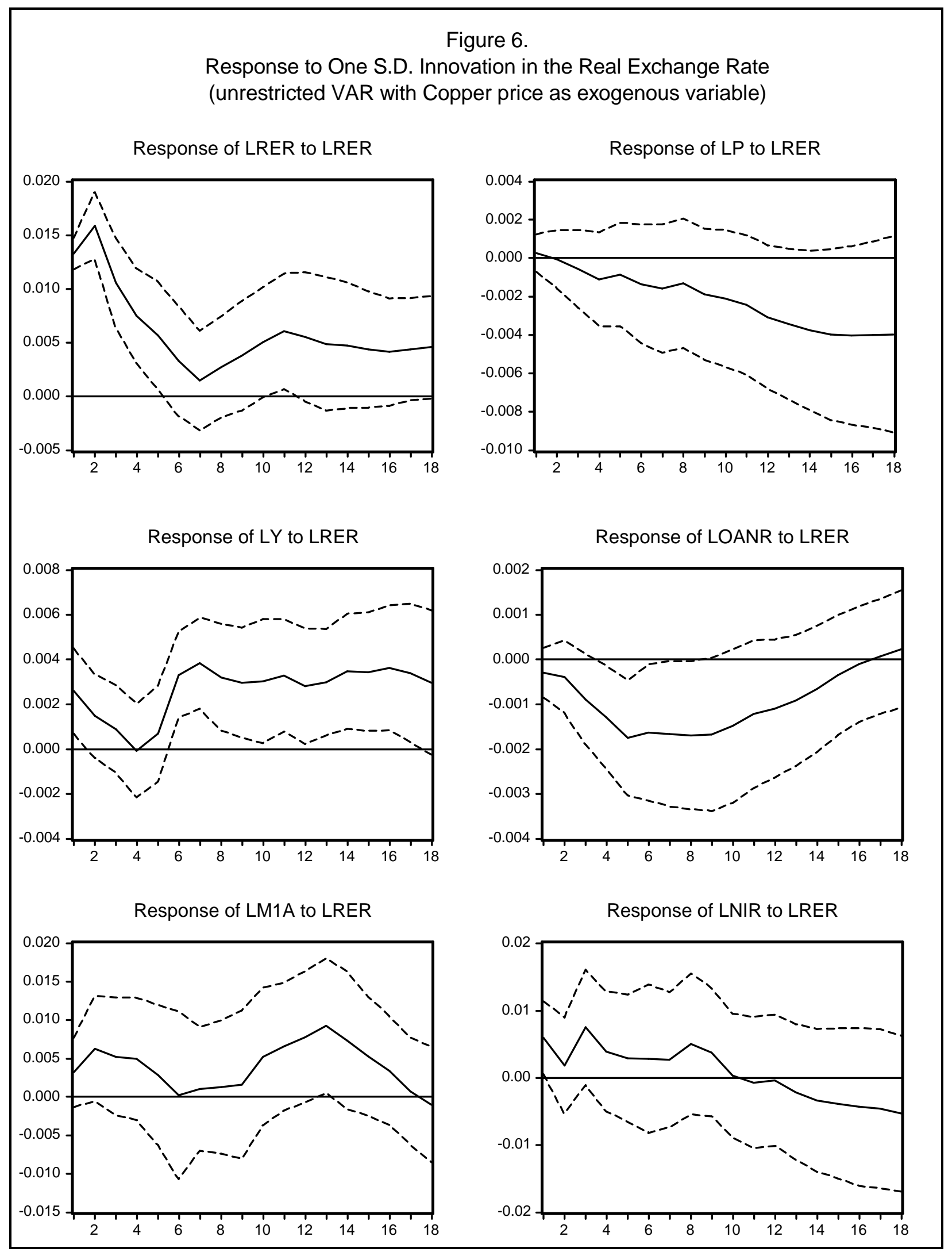


Figure 7.

Response to One S.D. Innovation in the Nominal Exchange Rate

Response of SHOCKEXR to SHOCKEXR

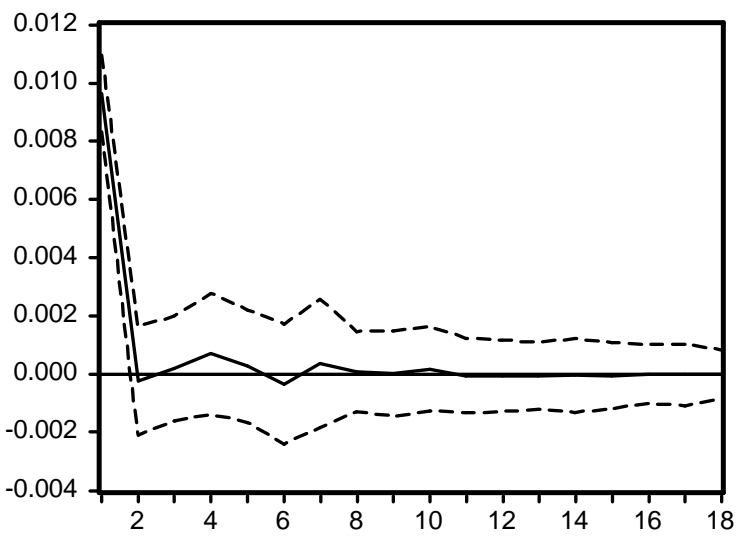

Response of LY to SHOCKEXR

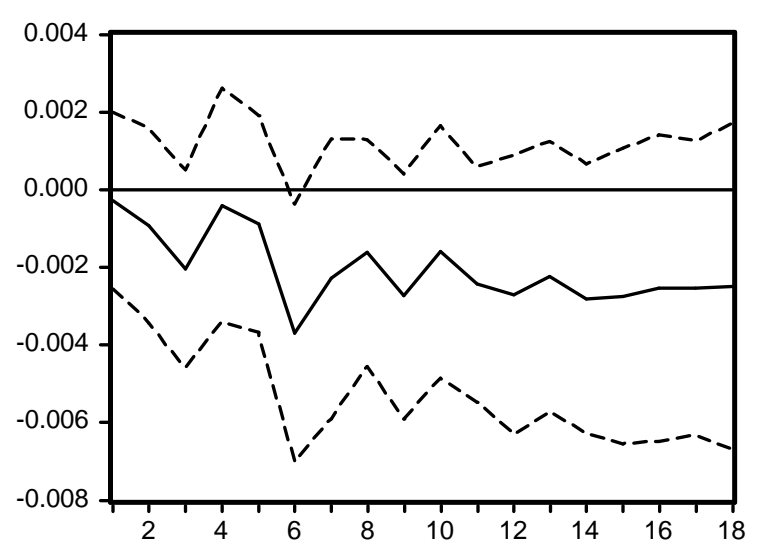

Response of LM1A to SHOCKEXR

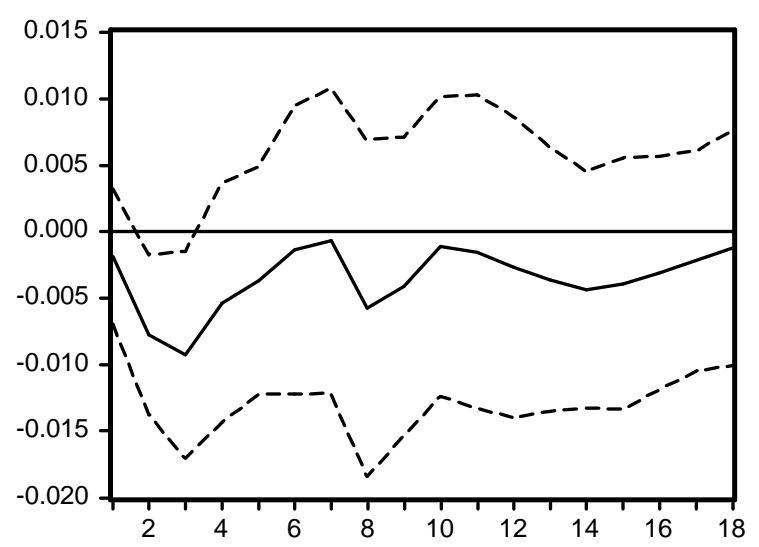

Response of LP to SHOCKEXR

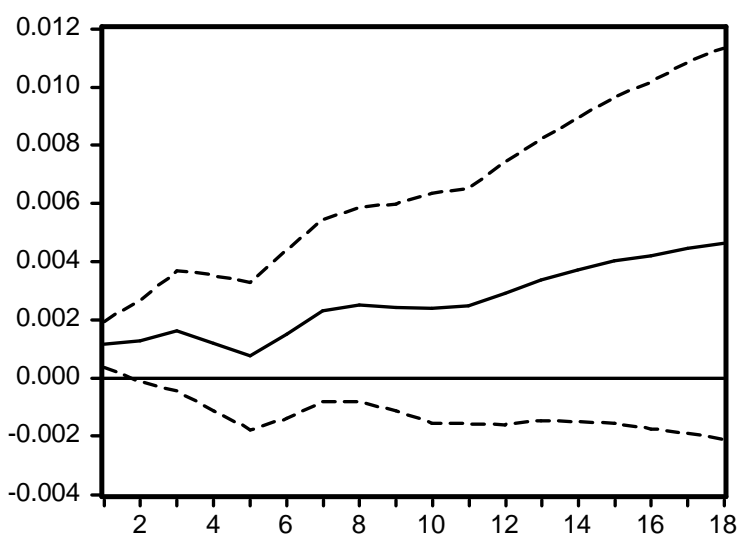

Response of LOANR to SHOCKEXR

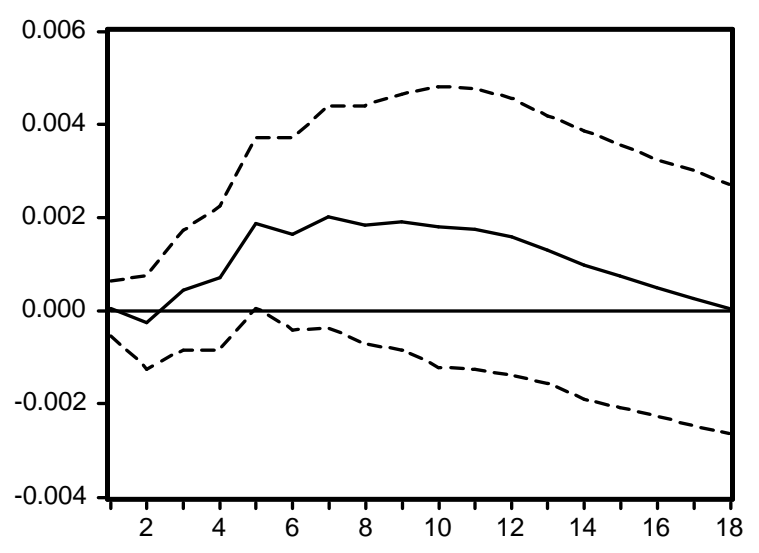

Response of LNIR to SHOCKEXR

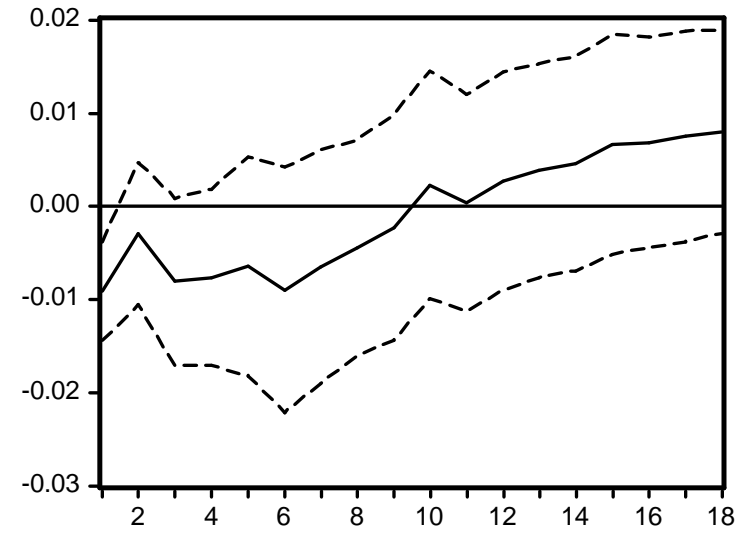


